\title{
Fixed Point Results for Contractive Type Mappings in Dislocated Metric Spaces
}

\author{
Asha Rani \\ SRM University, \\ Delhi NCR
}

\author{
Asha Rani \\ SRM University, \\ Delhi NCR
}

\begin{abstract}
In this paper we present fixed point results for generalized $\alpha-\psi-$ contractive type mappings in dislocated metric spaces. We also provide some examples to illustrate our results.
\end{abstract}

\section{Keywords}

Fixed point; dislocated metric space; $\alpha-\psi-$ contractive mapping

\section{INTRODUCTION}

Fixed point theory is one of the most dynamic research subject in non linear analysis and many fruitful results have come into the literature in the last few decades. The most remarkable result was given by Banach [1] in 1922 as Banach contraction principle. Later on, many generalization of Banach contraction Principle came into existence in the literature [2-4]. Samet et al.[5] introduced the notion of $\alpha-\psi$ contraction mappings and proved the related fixed point theorems.

In 2000, P. Hitzler and A.K. Seda [6] introduced the concept of dislocated metric space and generalized of well known Banach Contraction Principle in this space, which played a key role in the development of logic programming semantics. In this paper, we generalize the concept of $\alpha-\psi$ mappings as generalized $\alpha-\psi-$ contractive mappings in the setting of dislocated metric spaces.

\section{PRELIMINARIES}

Definition 2.1 [5] Let $\psi$ be a family of functions $\psi:[0, \infty) \rightarrow$ $[0, \infty)$ satisfying the following conditions:
(i) $\quad \psi$ is nondecreasing;
(ii) $\quad \sum_{n=1}^{\infty} \psi^{n}<\infty$ for each $t>0$, where $\psi^{n}$ is the nth iterate of $\psi$;

Definition 2.2 [5] Let $\mathrm{T}: \mathrm{X} \rightarrow \mathrm{X}$ and $\alpha: \mathrm{X} \times \mathrm{X} \rightarrow[0, \infty)$. we say that $\mathrm{T}$ is $\alpha$-admissible if for allx, $\mathrm{y} \in \mathrm{X}$, we have

$$
\alpha(\mathrm{x}, \mathrm{y}) \geq 1 \quad \Rightarrow \quad \alpha(\mathrm{Tx}, \mathrm{Ty}) \geq 1 \text {. }
$$

Hitzler and Seda [6] introduced the concept of dislocated metric space (d-metric space) as follows:

Definition 2.3 [6] Let $X$ be a non empty set and let $d: X \times$ $X \rightarrow[0, \infty)$ be a function and for all $x, y, z \in X$, the following conditions are satisfied:
(1) $d(x, y)=d(y, x)$
(2) $d(x, y)=d(y, x)=0$;
(3) $d(x, y) \leq d(x, z)+d(z, y)$;

Then $d$ is called dislocated metric (or simply d-metric) on $\mathrm{X}$ and the pair $(X, d)$ is called dislocated metric space.
Example $2.4[6]$ Let $(X, d)$ be a metric space. The function $f: X \times X \rightarrow \mathbb{R}^{+}$, defined as

$d(x, y)=\max (x, y) ; \quad$ for all $x, y \in X$ is a d-metric on $X$.

Definition 2.5[6] A sequence $\left\{x_{n}\right\}$ in a d-metric space $(X, d)$ is said to be d-convergent if for every given $\in>0$ there exist an $n \in N$ and $x \in X$ such that $d\left(x_{n}, x\right)<\in$ for all $n>N$ and it is denoted by $\lim _{n \rightarrow \infty} x_{n}=x$ or $x_{n} \rightarrow x$ as $n \rightarrow \infty$

Definition 2.6 [6] A sequence $\left\{x_{n}\right\}$ in a d-metric space $(X, d)$ is said to be d-Cauchy sequence if for every $\in>0$ there exist $n_{0} \in N$ such that $d\left(x_{n}, x_{m}\right)<\in$ for all $m, n \in n_{0}$

Definition 2.7 [6] A d-metric space $(X, d)$ is called complete if every Cauchy sequence is convergent.

Lemma 2.8 [6] Let $(X, d)$ be a d-metric space, $\left(x_{n}\right)$ be a sequence in $\mathrm{X}$ and $x \in X$. Then $x_{n} \rightarrow x(n \rightarrow \infty)$ if and only if $d\left(x_{n}, x\right) \rightarrow 0(n \rightarrow \infty)$

Lemma 2.9 [6] Let $(X, d)$ be a d-metric space and let $\left(x_{n}\right)$ be a sequence in $X$. If the sequence $\left(x_{n}\right)$ is convergent then the limit point is unique.

Theorem 2.10 [6] Let $(X, d)$ be a complete d-metric space and let $T: X \rightarrow X$ be a mapping satisfying the following condition for all $x, y \in X$ :

$$
d(T x, T y) \leq k d(x, y),
$$

where $k \in[0,1)$. then $T$ has a unique fixed point.

\section{MAIN RESULT}

We introduce the concept of generalized $\alpha-\psi$-contractive type mappings as follows. Definition 3.1. $\operatorname{Let}(X, d)$ be a dmetric space and $T: X \rightarrow X$ be a given mapping. We say that $T$ is a generalized $\alpha-\psi-$ contractive mapping if there exist two functions $\alpha: X \times X \rightarrow(0, \infty)$ and $\psi \in \Psi$ such that for all $x, y \in X$, and we have $\alpha(x, y) d(T x, T y) \leq \psi(M(x, y))$ (1)

Where

$M(x, y)=\max \left\{d(x, y), \frac{d(x, T x)+d(y, T y)}{2}, \frac{d(x, T y)+d(y, T x)}{2}\right\}$.

Remark 3.2. Clearly, since $\psi$ is non-decreasing, every $\alpha-\psi-$ contractive mapping is a generalized $\alpha-$ $\psi$-contractive mapping.

Theorem 3.3. Let $(X, d)$ be a d-complete metric space. Suppose that $T: X \rightarrow X$ is a generalized $\alpha-\psi-$ contractive mapping and satisfies the following conditions:
(i) $\quad T$ is $\alpha$ admissible;
(ii) there exists $x_{0} \in X$ such that $\alpha\left(x_{0}, T x_{0}\right) \geq 1$;
(iii) $\quad T$ is d-continuous.

Then there exists $u \in X$ such that $T u=u$. 
Proof. Let $x_{0} \in X$ such that $\alpha\left(x_{0}, T x_{0}\right) \geq 1$ (such a point exists from condition (ii)). Define the sequence $\left\{x_{n}\right\}$ in $X$ by $x_{n+1}=T x_{n}$ for all $n \geq 0$. If $x_{n_{0}}=x_{n_{0}+1}$ for some $n_{0}$, then $u=x_{n_{0}}$ is a fixed point of $T$. So, we can assume that $x_{n} \neq x_{n+1}$ for all $n$. Since Tis $\alpha$-admissible, we have

$$
\begin{aligned}
& \alpha\left(x_{0}, x_{1}\right)=\alpha\left(x_{0}, T x_{0}\right) \geq 1 \\
\Rightarrow \alpha\left(T x_{0}, T x_{1}\right) & =\alpha\left(x_{1}, x_{2}\right) \geq 1
\end{aligned}
$$

Inductively, we have

$$
\alpha\left(x_{n}, x_{n+1}\right) \geq 1, \text { for all } n=0,1,2 \ldots
$$

From (1) and (3), it follows that for all $n \geq 1$, we have

$$
\begin{array}{r}
\quad d\left(x_{n+1}, x_{n}\right)=d\left(T x_{n}, T x_{n-1}\right) \\
\leq \alpha\left(x_{n}, x_{n-1}\right) d\left(T x_{n}, T x_{n-1}\right) \\
\leq \psi\left(M\left(x_{n}, x_{n-1}\right)\right)
\end{array}
$$

On the other hand, we have

$$
\begin{aligned}
& M\left(x_{n}, x_{n-1}\right) \\
& =\max \left\{\begin{array}{c}
d\left(x_{n}, x_{n-1}\right), \frac{d\left(x_{n}, T x_{n}\right)+d\left(x_{n-1}, T x_{n-1}\right)}{2}, \\
\frac{d\left(x_{n}, T x_{n-1}\right)+d\left(x_{n-1}, T x_{n}\right)}{2}
\end{array}\right\} \\
& =\max \left\{\begin{array}{c}
d\left(x_{n}, x_{n-1}\right), \frac{d\left(x_{n}, x_{n+1}\right)+d\left(x_{n-1}, x_{n}\right)}{2}, \\
\frac{d\left(x_{n-1}, x_{n+1}\right)}{2}
\end{array}\right\}, \\
& \leq \max \left\{d\left(x_{n}, x_{n-1}\right), \frac{d\left(x_{n}, x_{n+1}\right)+d\left(x_{n-1}, x_{n}\right)}{2}\right\},
\end{aligned}
$$

From (4) and taking in consideration that $\psi$ is a nondecreasing function, we get that

$d\left(x_{n+1}, x_{n}\right) \leq \psi\left(\max \left\{\begin{array}{l}d\left(x_{n}, x_{n-1}\right), \\ d\left(x_{n}, x_{n+1}\right)\end{array}\right\}\right)$

For all $n \geq 1$. If for some $n \geq 1$, we have $d\left(x_{n}, x_{n-1}\right) \leq$ $d\left(x_{n}, x_{n+1}\right)$, from (6), we obtain that

$$
\begin{gathered}
d\left(x_{n+1}, x_{n}\right) \leq \psi\left(d\left(x_{n}, x_{n+1}\right)\right) \\
<d\left(x_{n}, x_{n+1}\right),
\end{gathered}
$$

a contradiction. Thus, for all $n \geq 1$, we have

$$
\max \left\{\begin{array}{l}
d\left(x_{n}, x_{n-1}\right), \\
d\left(x_{n}, x_{n+1}\right)
\end{array}\right\}=d\left(x_{n}, x_{n-1}\right)
$$

Using (6) and (8), we get that

$$
d\left(x_{n+1}, x_{n}\right) \leq \psi\left(d\left(x_{n}, x_{n-1}\right)\right),
$$

for all $n \geq 1$. By induction, we get

$d\left(x_{n+1}, x_{n}\right) \leq \psi^{n}\left(d\left(x_{1}, x_{0}\right)\right)$,

for all $n \geq 1$

From (10) and using the triangular inequality, for all $k \geq 1$, we have

$$
\begin{gathered}
d\left(x_{n}, x_{n+k}\right) \leq d\left(x_{n}, x_{n+1}\right)+\cdots . .+d\left(x_{n+k-1}, x_{n+k}\right) \\
\leq \sum_{p=n}^{n+k-1} \psi^{p}\left(d\left(x_{1}, x_{0}\right)\right), \\
\leq \sum_{p=n}^{\infty} \psi^{p}\left(d\left(x_{1}, x_{0}\right)\right) \rightarrow 0 \text { as } n \rightarrow \infty
\end{gathered}
$$

This implies that $\left\{x_{n}\right\}$ is a Cauchy sequence in the d-metric space $(X, d)$. since $(X, d)$ is complete, there exist $u \in X$ such that $\left\{x_{n}\right\}$ is $\mathrm{d}$-convergent to $u$. since $T$ is $\mathrm{d}$-continuous, it follows that $\left\{T x_{n}\right\}$ is d-convergent to $T u$. by the uniqueness of the limit, we get $u=T u$, that is, $u$ is a fixed point of $T$.

The next theorem does not require continuity of $T$.

Theorem 3.4 Let $(X, d)$ be a complete d-metric space. Suppose that $T: X \rightarrow X$ is a generalized $\alpha-\psi$-contractive mapping and the following conditions satisfies :

(i) $\quad T$ is $\alpha$-admissible;

(ii) there exists $x_{0} \in X$ such that $\alpha\left(x_{0}, T x_{0}\right) \geq 1$;

(iii) if $\left\{x_{n}\right\}$ is a sequence in $X$ such that $\alpha\left(x_{n}, x_{n+1}\right) \geq 1$ for all $n$ and $x_{n} \rightarrow x$ as $n \rightarrow \infty$, then there exists a subsequence $\left\{x_{n_{k}}\right\}$ of $\left\{x_{n}\right\}$ such that $\alpha\left(x_{n_{k}}, x\right) \geq 1$ for all $k$. Then there exist $u \in X$ such that $T u=u$.

Proof Following the proof of theorem 3.3, we know that the sequence $\left\{x_{n}\right\}$ defined by $x_{n+1}=T x_{n}$ for all $n \geq 0$ is a Cauchy sequence in the complete d-metric space $(X, d)$ that is d-convergent to $u \in X$, From (3.3) and condition (iii), there exists a subsequence $\left\{x_{n_{k}}\right\}$ of $\left\{x_{n}\right\}$ such that $\alpha\left(x_{n_{k}}, x\right) \geq 1$ for all $k$

Applying (1), for all $k$, we get that

$$
\begin{aligned}
d\left(x_{n_{k}+1}, T u\right) & \leq d\left(T x_{n_{k}}, T u\right) \\
\leq & \alpha\left(x_{n_{k}}, u\right) d\left(T x_{n_{k}}, T u\right) \\
& \leq \psi\left(M\left(x_{n_{k}}, u\right)\right)
\end{aligned}
$$

where

$M\left(x_{n_{k}}, u\right)=\max \left\{\begin{array}{c}d\left(x_{n_{k}}, u\right), \frac{d\left(x_{n_{k}+1}, x_{n_{k}}\right)+d(u, T u)}{2}, \\ \frac{d\left(x_{n_{k}}, T u\right)+d\left(u, x_{n_{k}+1}\right)}{2}\end{array}\right\}$.

Letting $k \rightarrow \infty$,in the above equality, we get that

$$
\lim _{k \rightarrow \infty} M\left(x_{n_{k}}, u\right)=\frac{d(u, T u)}{2} .
$$

Suppose that $d(u, T u)>0$. From (12), for $k$ large enough, we have $M\left(x_{n_{k}}, u\right)>0$, which implies that $\psi\left(M\left(x_{n_{k}}, u\right)\right)<$ $M\left(x_{n_{k}}, u\right)$. Thus, we have

$M\left(x_{n_{k}}, u\right)$

$$
d\left(x_{n_{k}+1}, T u\right)<
$$

Letting $k \rightarrow \infty$ in the above inequality, using (12), we obtain that

$$
d(u, T u) \leq \frac{d(u, T u)}{2}
$$

which is a contradiction. Thus we have $d(u, T u)=0$, that is, $u=T u$.

With the following example, we will show that hypotheses in Theorems 3.3 and 3.4 not guarantee uniqueness of the fixed point.

Example 3.5. Let $X=\{(1,0),(0,1)\} \subset \mathbb{R}^{2}$ be endowed with the Euclidean distance $d(x, y),(u, v)=|x+u|+|y+v|$ for all $(x, y),(u, v) \in X$. Obviously, $(X, d)$ is a complete metric space. The mapping $T(x, y)=(x, y)$ is trivially continuous 
and satisfies for any $\psi \in \Psi$ $\alpha((x, y),(u, v)) d(T(x, y), T(u, v))$

$\leq \psi(M((x, y),(u, v)))$

for all $(x, y),(u, v) \in X$, where

$$
\alpha(x, y)= \begin{cases}1 & (x, y)=(u, v) \\ 0 & (x, y) \neq(u, v)\end{cases}
$$

Thus $T$ is a generalized $\alpha-\psi$-contractive mapping. On the other hand, for all $(x, y),(u, v) \in X$, we have

$$
\begin{gathered}
\alpha((x, y),(u, v)) \geq 1 \\
\rightarrow(x, y)=(u, v) \\
\rightarrow T(x, y)=T(u, v) \\
\rightarrow \alpha(T(x, y), T(u, v)) \geq 1 .(17)
\end{gathered}
$$

Thus $\mathrm{T}$ is $\alpha$-admissible. Moreover, for all $(x, y) \in X$, we have

$$
\alpha((x, y,) T(x, y)) \geq 1 .
$$

Then the assumptions of Theorem 3.3 are satisfied. Note that the assumptions of Theorem 3.4 are also satisfied; indeed if $\left\{x_{n}, y_{n}\right\}$ is a sequence in $X$ that converges to some point $(x, y) \in X$ with $\alpha\left(\left(x_{n}, y_{n}\right),\left(x_{n+1}, y_{n+1}\right)\right) \geq 1$ for all $\mathrm{n}$, then, from the definition of $\alpha$ we have $\left(x_{n}, y_{n}\right)=(x, y)$ for all $n$, which implies that $\alpha\left(\left(x_{n}, y_{n}\right),(x, y)\right)=1$ for all $n$. However, in this case, $T$ has two fixed points in $X$.

For the uniqueness of a fixed point of a generalized $\alpha-$ $\psi$-contractive mapping, we will consider the following hypothesis.

(A) For all $x, y \in \operatorname{Fix}(T)$, there exists $z \in X$ such that $\alpha(x, z) \geq 1$ and $\alpha(y, z) \geq 1$.

Theorem 3.6. Adding condition (A) to the hypotheses of Theorem 3.3 (resp., Theorem 3.4), one has obtains that $u$ is the unique fixed point of $T$.

Proof. Suppose that $v$ is another fixed point of $T$. From (A), there exists $z \in X$ such that

$$
\alpha(u, z) \geq 1, \alpha(v, z) \geq 1
$$

Since $T$ is $\alpha$-admissible, from (18), we have

$$
\alpha\left(u, T^{n} z\right) \geq 1, \alpha\left(v, T^{n} z\right) \geq 1
$$

Define the sequence $\left\{z_{n}\right\}$ in $X$ by

$z_{n+1}=T z_{n}$ for all $n \geq 0$ and $z_{0}=z$.

From (19), for all $n$, we have

$$
\begin{array}{r}
d\left(u, Z_{n+1}\right)=d\left(T u, T z_{n}\right) \\
\leq \alpha\left(u, z_{n}\right) d\left(T u, T z_{n}\right) \leq \psi\left(M\left(u, z_{n}\right)\right)(20)
\end{array}
$$

On the other hand, we have

$$
\begin{aligned}
& \quad M\left(u, z_{n}\right)=\max \left(\begin{array}{c}
d\left(u, z_{n}\right), \frac{d\left(z_{n}, z_{n+1}\right)}{2}, \\
\frac{d\left(u, z_{n+1}\right)+d\left(z_{n}, u\right)}{2}
\end{array}\right), \\
& \leq \max \left(d\left(u, z_{n}\right), \frac{d\left(u, z_{n+1}\right)+d\left(z_{n}, u\right)}{2}\right), \\
& \leq \max \left(d\left(u, z_{n}\right), d\left(u, z_{n+1}\right)\right)
\end{aligned}
$$

Using the above inequality, (20) and the monotone property of $\psi$, we get that

$d\left(u, z_{n+1}\right) \leq \psi\left(\max \left\{d\left(u, z_{n}\right), d\left(u, z_{n+1}\right)\right\}\right)$

for all $n$. Without restriction to the generality, we can suppose that

$$
\begin{aligned}
& d\left(u, z_{n}\right)>0 \text { for all } n \text {. If } \\
& \quad \max \left\{d\left(u, z_{n}\right), d\left(u, z_{n+1}\right)\right\}=d\left(u, z_{n+1}\right),
\end{aligned}
$$

we get from (22) that

$d\left(u, z_{n+1}\right) \leq \psi\left(d\left(u, z_{n+1}\right)\right)<d\left(u, z_{n+1}\right)$

which is a contradiction. Thus we have

$$
\begin{aligned}
& \max \left\{d\left(u, z_{n}\right), d\left(u, z_{n+1}\right)\right\}=d\left(u, z_{n}\right), \text { and } \\
& d\left(u, z_{n+1}\right) \leq \psi\left(d\left(u, z_{n}\right)\right)
\end{aligned}
$$

for all $n$. This implies that

$d\left(u, z_{n}\right) \leq \psi^{n}\left(d\left(u, z_{0}\right)\right)$

for all $n \geq 1$.

Letting $n \rightarrow \infty$ in the above inequality, we obtain that

$\lim _{n \rightarrow \infty} d\left(z_{n}, u\right)=0$.

Similarly, one can show that

$\lim _{n \rightarrow \infty} d\left(z_{n}, v\right)=0$.

From (26) and (27), it follows that $u=v$. Thus we proved that $u$ is the unique fixed point of $T$.

Example 3.7. Let $X=[0,1]$ be endowed with the standard metric $d(x, y)=|x+y|$ for all $x, y \in X$. Obviously, $(X, d)$ is a complete metric space. Define the mapping $T: X \rightarrow X$ by

$T x=\left\{\begin{array}{lr}\frac{1}{4} & \text { if } x \in[0,1), \\ 0 & \text { if } x=1\end{array}\right.$

In this case, $T$ is not continuous. Define the mapping $\alpha: X \times$ $X \rightarrow[0, \infty)$ by

$\alpha(x, y)=\left\{\begin{array}{r}1 \quad \text { if }(x, y) \in\left\{\begin{array}{c}\left(\left[0, \frac{1}{4}\right] \times\left[\frac{1}{4}, 1\right]\right) \cup \\ \left(\left[\frac{1}{4}, 1\right] \times\left[0, \frac{1}{4}\right]\right)\end{array}\right\} \\ \text { otherwise }\end{array}\right.$

We will prove that

(i) $\quad T: X \rightarrow X$ is a generalized $\alpha$ - $\psi$-contractive mapping, where $\psi(t)=t / 2$ for all $t \geq 0$;

(ii) $T$ is $\alpha$-admissible;

(iii) there exists $x_{0} \in X$ such that $\alpha\left(x_{0}, T x_{0}\right) \geq 1$;

(iv) if $\left\{x_{n}\right\}$ is a sequence in $X$ such that $\alpha\left(x_{n}, x_{n+1}\right) \geq$ 1 for all $n$ and $x_{n} \rightarrow x \in X$ as $n \rightarrow+\infty$, then there exists a subsequence $\left\{x_{n_{k}}\right\}$ of $\left\{x_{n}\right\}$ such that $\alpha\left(x_{n_{k}}, x\right) \geq 1$ for all $k$;

(v) condition (A) is satisfied

Proof of (i). To show (i), we have to prove that (2.1) is satisfied for every $x, y \in X$. If $x \in[0,1 / 4]$ and $y=1$, we have

$$
\begin{aligned}
\alpha(x, y) d(T x, T y)= & d(T x, T y)=\left|0-\frac{1}{4}\right|=\frac{1}{4} d(x, T x) \\
& \leq \varphi(M(x, y))
\end{aligned}
$$


Then (2.1) holds.

If $x=1$ and $y \in[0,1 / 4]$, we have

$$
\begin{aligned}
\alpha(x, y) d(T x, T y)= & d(T x, T y)=\left|0-\frac{1}{4}\right|=\frac{1}{4} d(x, T x) \\
& \leq \varphi(M(x, y))
\end{aligned}
$$

Then (2.1) holds also in this case. The other cases are trivial. Thus (2.1) is satisfied for every $x, y \in X$.

Proof of (ii). Let $(x, y) \in X \times X$ such that $\alpha(x, y) \geq 1$. From the definition of $\alpha$, we have two cases.

Case 1 (if $(x, y) \in[0,1 / 4] \times[1 / 4,1]$. In this case, we have $(T x, T y)=\{(1 / 4,0) \times(1 / 4,1)\}$, which implies that $\alpha(T x, T y)=1$.

Case 2 (if $(x, y) \in[1 / 4,1] \times[0,1 / 4]$. In this case, we have

$(T x, T y)=\{(0,1 / 4) \times(1,1 / 4)\}$,

which implies that $\alpha(T x, T y)=1$.

So, in all cases, we have $\alpha(T x, T y) \geq 1$. Thus $\mathrm{T}$ is $\alpha$ admissible.

Proof of (iii). Taking $x_{0}=0$, we have $\alpha\left(x_{0}, T x_{0}\right)=$ $\alpha(0,1 / 4)=1$.

Proof of (iv). Let $\left\{x_{n}\right\}$ be a sequence in $X$ such that $\alpha\left(x_{n}, x_{n+1}\right) \geq 1$ for all $\mathrm{n}$ and $x_{n} \rightarrow x$ as $n \rightarrow+\infty$ for some $x \in X$. From the definition of $\alpha$, for all $n$,

we have $\left(x_{n}, x_{n+1}\right) \in\left\{\left(\left[0, \frac{1}{4}\right] \times\left[\frac{1}{4}, 1\right]\right) \cup\left(\left[\frac{1}{4}, 1\right] \times\left[0, \frac{1}{4}\right]\right)\right\}$.

Since $\left(\left[0, \frac{1}{4}\right] \times\left[\frac{1}{4}, 1\right]\right) \cup\left(\left[\frac{1}{4}, 1\right] \times\left[0, \frac{1}{4}\right]\right)$ is a closed set with respect to the Euclidean metric, we get that

$(x, y) \in\left(\left[0, \frac{1}{4}\right] \times\left[\frac{1}{4}, 1\right]\right) \cup\left(\left[\frac{1}{4}, 1\right] \times\left[0, \frac{1}{4}\right]\right)$. which implies that $x=1 / 4$. Thus, we have $\alpha\left(x_{n}, x\right) \geq 1$ for all $n$.

Proof of (v). Let, $(x, y) \in X \times X$.

It is easy to show that, for $z=1 / 4$,

We have $\alpha(x, z)=\alpha(y, z)=1$.

So, condition (A) is satisfied.

Conclusion. Now, all the hypotheses of Theorem 3.6 are satisfied; thus $T$ has a unique fixed point $u \in X$. In this case, we have $u=1 / 4$.

\section{REFERENCES}

[1] Banach S., "Surles operations dans les ensembles abstraites et leurs applications", Fund. Math., 3 (1922), 133-187.

[2] Kannan R., "Some results on fixed points", Bull. Cal. Math. Soc., 60 (1968), 71-76.

[3] Zamfirescu T., "Fixed Point Theorems In Metric Spaces”, Arch. Math., 23 (1972), 292-298.

[4] Rhoades B.E., "A fixed point theorem for generalized metric spaces", Internat. J. Math. and Math. Sci., 19 (3) (1996), 457-460.

[5] Samet B.,Vetro C. and Vetro P., "Fixed point theorems for $\alpha-\psi$-contractive mappings," Nonlinear Analysis,75(2012), 2154-2165.

[6] Hitzler P. and Seda A.K., Dislocated Topologies, J. Electr. Engg., 51 (12/s),(2000), 3-7. 